\title{
Research on Influencing Factors of Adoption Behavior of Mobile Readers Based on Meta-Analysis
}

\author{
Haihua Zhou, ${ }^{1,2}$ Jing Liu $\mathbb{D}^{3},{ }^{3}$ and Xiaodong Cui ${ }^{2}$ \\ ${ }^{1}$ Business School, Nanjing University, No. 163 Xianlin Avenue, Qixia District, Nanjing 210012, China \\ ${ }^{2}$ Business School, Nanjing Xiaozhuang University, No. 3601 Hongjing Avenue, Jiangning District, Nanjing 211171, China \\ ${ }^{3}$ School of Management, Nanjing University of Posts and Telecommunications, No. 9 Wenyuan Road, Yadong New District, \\ Nanjing 210023, China \\ Correspondence should be addressed to Jing Liu; liuj_m@njupt.edu.cn
}

Received 30 June 2021; Revised 28 August 2021; Accepted 1 September 2021; Published 13 September 2021

Academic Editor: Lingwei $\mathrm{Xu}$

Copyright (C) 2021 Haihua Zhou et al. This is an open access article distributed under the Creative Commons Attribution License, which permits unrestricted use, distribution, and reproduction in any medium, provided the original work is properly cited.

\begin{abstract}
Many scholars have conducted extensive research on the adoption behavior of mobile readers, and there are obvious differences in the degree and direction of conclusions drawn from different individual studies. In this study, a meta-analysis method was used to comprehensively analyze a total of 74,964 independent samples of 31 relevant empirical research documents at home and abroad. The results show that the main influencing factors of mobile reading are perceived usefulness, perceived ease of use, perceived mobility, perceived entertainment, social influence, cognitive adjustment, perceived value, usage attitude, interface design, etc. Cognitive adjustment and usage attitude have the greatest impact on intention to use, followed by perceived usefulness, perceived mobility, subjective norms, perceived ease of use; perceived ease of use has a significant positive impact on perceived usefulness; interface design has a significant positive effect on perceived ease of use; behavioral intention has a significant positive effect on actual behavior; and perceived usefulness and perceived ease of use have a significant positive effect on usage attitude.
\end{abstract}

\section{Introduction}

It is generally known that the fifth-generation (5G) mobile wireless networks have been widely deployed [1]. With the development of the fifth-generation (5G) mobile wireless networks, mobile reading quickly becomes convenient. Mobile reading refers to reading with mobile terminal devices such as mobile phones, tablets, and e-readers at any time and any place through wireless Internet. Reading content includes e-books, audio books, news, and magazines. In recent years, with the healthy and stable development of China's mobile commerce market, mobile reading, as one of its important applications, has been favored by many users due to its convenience and flexibility, and scale and speed of development of mobile reading have made great progress. According to the research results of iiMedia Consulting's "Special Research Report on the Development of China's Mobile Reading Industry in 2020," China's online reading population has reached 530 million in 2020. The 18th National Reading Survey of the China Press and Publication Research Institute found that mobile reading and online reading are the main methods of digital reading for adult citizens in 2020, and the proportion of middle-aged and elderly people in the digital reading population has increased. Among them, $76.7 \%$ of adult citizens read on mobile phones, an increase of $0.6 \%$ from $76.1 \%$ in 2019. Among the groups who have experienced digital reading (online reading, mobile phone reading, e-reading, Pad reading, WeChat Mini Program, etc.), people aged 50 and above accounted for $23.2 \%$, an increase of 2.8 from $20.4 \%$ in 2019. Mobile reading has become the mainstream reading platform. Major domestic reading platforms such as China Literature, Palm Media Technology, and Migu Digital Media Co. Ltd. are striving to attract readers and expand the scale of users. Scholars have conducted a lot of research on the influencing factors that affect the behavior of mobile readers. In the early days of the development of mobile Internet, when smart phones had 
just been popularized and the cost of using mobile devices such as mobile phones was relatively high, domestic scholars mainly studied the factors affecting the willingness or behavior of mobile reading. With the development of mobile Internet technology, especially with the popularization of new technologies such as $5 \mathrm{G}$ in the mobile Internet, mobile reading has gradually developed into willingness to pay. Therefore, in recent years, scholars have mainly studied the influencing factors of willingness to pay or behavior. Since the use of mobile networks in foreign countries is not as convenient as in China, most of the research conducted by foreign scholars focuses on the willingness or behavior of using e-readers such as Kindle. Most of these studies are based on Technology Acceptance Model (TAM) and Unified Theory of Acceptance and Use of Technology Model (UTAUT). The conclusions are quite different about the factors that affect users' willingness or behavior to adopt mobile reading in different studies. Meta-analysis methods can analyze all documents based on the technology acceptance model, sort out the framework of research results that affect mobile reading intentions or behaviors, and make recommendations to major mobile digital platform service providers, network service providers, and other relevant departments based on the research results.

Based on the existing Chinese and English literature, this paper finally builds a meta-analysis-based comprehensive model of the influencing factors of mobile reading on the basis of Technology Acceptance Model (TAM) and Unified Theory of Acceptance and Use of Technology Model (UTAUT), which is a powerful supplement and expansion of the existing theoretical model of influencing mobile digital reading adoption behavior. This article is based on theoretical modeling and empirical research based on the conclusions of factors influencing the adoption of mobile reading, which is an extremely important reference for mobile service providers. Mobile service providers can carry out targeted marketing activities based on this research conclusion to promote mobile reading services. At the same time, the research in this article also provides a reference for the healthy development of the mobile reading market and the supervision of the regulatory agencies, so as to make the regulators attach great importance to the mobile reading market.

The main contributions of this research: (1) systematically reviews 31 Chinese and English literatures on mobile reading influencing factors based on Technology Acceptance Model (TAM) and Unified Theory of Acceptance and Use of Technology Model (UTAUT) and structural equation models; (2) a total of 194 path relationships were sorted out in 31 articles, with 74964 samples. The same path relationships were merged, and 58 path relationships between 18 variables were finally integrated. Among these path relations, the path relationships with the number of studies greater than or equal to 5 were selected for research, and 13 path relationships among 11 variables were finally determined. The heterogeneity test was performed and the random-effect model was determined; (3) finally, a comprehensive model diagram of the influencing factors of mobile reading based on meta-analysis was established, and the meta-analysis of descriptive statistics, reliability analysis, effect value, and failure safety factor is carried out on these path relations.

\section{Literature Review}

At present, the model of the influencing factors of the willingness to adopt or the willingness to pay for mobile reading is mainly based on Technology Acceptance Model (TAM) and Unified Theory of Acceptance and Use of Technology Model (UTAUT). The model of the willingness to continue to adopt or the willingness to pay is based on the Expectation Confirmation Theory and is not included in this article. Therefore, the following models and literature are reviewed based on the technology acceptance model and the integrated technology acceptance model.

2.1. Model Introduction. The Technology Acceptance Model (TAM) was proposed by Davis [2] and other scholars in 1989 on the basis of the Theory of Reasoned Action (TRA) and the Theory of Planned Behavior (TPB), as shown in Figure 1. In Figure 1, Technology Acceptance Model believes that system use is determined by behavioral intention, and behavioral intention is determined by both attitude toward using and perceived usefulness, and attitude toward using is determined by perceived usefulness and ease of use. Sexuality is jointly determined, the usefulness of perception is jointly determined by the ease of perception and external variables, and the ease of perception is determined by external variables. External variables include system design characteristics, user characteristics (including perception forms and other personality characteristics), task characteristics, the nature of the development or execution process, policy influence, organizational structure, etc., which are the internal beliefs, attitudes, and intentions that exist in the technology acceptance model. It establishes a connection with the differences between different individuals, environmental constraints, and controllable interference factors. The model can be used to predict the degree of individual adoption of information systems or information technology, and its main variables are perceived usefulness, perceived ease of use, use attitude, behavior intention, and use behavior. Exogenous variables refer to the factors that affect the personal perceived usefulness and ease of use by the external environment of the model. External variables provide a link between beliefs, will, attitudes, environmental constraints, and controllable influencing factors within the technical model. It greatly improves the scalability of the technical model and provides the feasibility for the improvement of follow-up research.

Unified Theory of Acceptance and Use of Technology Model (UTAUT) was proposed by Venkatesh [3] and other scholars in 2003 in integrated existing Theory of Reasoned Action (TRA), Theory of Planned Behavior (TPB), Social Cognitive Theory (Social Cognition), Cognition Theory (SCT), and Technology Acceptance Model (TAM). These theories have used several different technological and contextual factors that influence the adoption of 


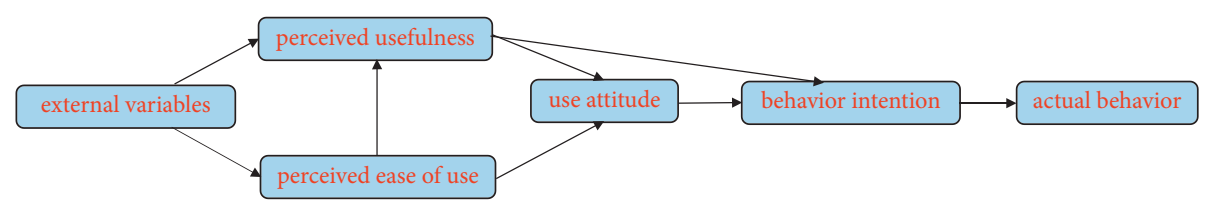

FIgURE 1: Technology acceptance model.

technologies in individual and organizational contexts [4]. The model includes four independent variables-performance expectations, effort expectations, social impact, and convenience conditions, and four adjustment variables-gender, age, experience, and voluntary use. From the definition of the independent variables in this model, performance expectations are equivalent to the perceived usefulness in the technology acceptance model, and effort expectations are equivalent to the perceived ease of use in the technology acceptance model. After the model was proposed, it has been widely used in research on user adoption and behavior, such as mobile commerce, mobile health services, mobile finance, mobile government, and online learning.

2.2. Literature Review. Through the review of existing literature, many scholars have carried out empirical research based on TAM, UTAUT, and the extended model based on these two models. The research variables and research conclusions are different. Scholars have used TAM to study the influencing factors of the adoption behavior intention of mobile reading activities. These influencing factors mainly include perceived ease of use, perceived usefulness, subjective norms, social influence, perceived mobility, perceived value, cognitive adjustment, and interface design. Most scholars have found that perceived ease of use and perceived usefulness have a positive and significant impact on usage intention [5-14], but the research conclusions of Xiong [5] do not support that perceived usefulness and perceived ease of use have a significant positive effect on intention to use. Han Chaoqun et al. [15] and Lao Guling et al. [16] support the positive and significant effect of perceived ease of use on behavior intention but do not support the positive and significant effect of perceived usefulness on behavior intention. Although the research conclusion of Williams et al. [17] support the positive and significant influence of perceived usefulness on behavior intention, it does not support the positive and significant influence of perceived ease of use on behavior intention. Subjective norms, social influences, etc., have a positive and significant impact on behavior intentions $[9,18-21]$, but the research conclusions of Han et al. [15] do not support the positive and significant influence of social influence on behavioral willingness. The research conclusions of Lao and Gao [16] do not support the positive and significant influence of subjective norms on behavior intentions. The research conclusions of Han et al. [15] and Lai et al. [22] support the positive and significant influence of perceived mobility on behavioral intentions, but Ge [23] and Chiang and Chen [19] found that the positive effect of perceived mobility on behavioral intention is not significant. Dong [24] empirically believes that perception tasks, performance expectations, community influence, promotion conditions, and perceived pleasure have a positive and significant impact on college students' mobile reading behavior, while the effect of effort expectation is not significant; however, Zhang [21] found that both performance expectations and effort expectations have a significant positive impact on users' willingness to pay. The research conclusions of Zheng [25], Huang and Fan [26], Wang et al. [27], Zhang [8], and Zhang et al. [13] support the perception of change. Usability has a positive and significant influence on usage attitude, while Liu et al. [20] do not support the positive and significant influence of perceived ease of use on usage attitude. Ye [28], Li and He [14], and Zheng [29] support the positive and significant impact of perceived value on behavioral intentions, but Zhao and Xie [30] did not support the positive and significant impact of perceived value on behavioral intentions. Scholars agree that interface design has a significant positive impact on perceived ease of use $[8,9,31,32]$, and most scholars believe that perceived ease of use has a significant positive impact on perceived usefulness $[11,22,26,33]$. The results of many studies $[8,34]$ support the positive and significant impact of cognitive regulation on behavioral intentions. All scholars in this study including Chen and Zhu [35] believe that the intention to use has a positive and significant impact on the use behavior. Through the review of the above literature, it is found that many scholars have different conclusions about which factors have significant influence on users' digital reading adoption behavior. Therefore, this article builds a comprehensive model based on the meta-analysis method on the influencing factors of the existing literature, and tries to draw more general conclusions that influence the adoption behavior of mobile reading.

\section{Methodology}

3.1. Research Methodology. Meta-analysis method (Comprehensive meta-analysis, CMA) is a secondary comprehensive analysis and involves evaluation of numerous individual studies [36]. When scholars conduct research on the same subject, there are different research results due to different sample sources, sample sizes, method models, and research perspectives [37]. The meta-analysis method can draw a more universal comprehensive research conclusion by integrating a large number of studies. Compared with the traditional literature analysis 
method, which mainly analyzes the research content based on the author's subjective judgment, the metaanalysis method is more objective and comprehensive [38]. Compared with traditional literature reviews and content analysis method, the meta-analysis method will screen the literature strictly, which can better avoid personal subjective thinking. The method makes the research conclusions more objective and universal. The paper uses the meta-analysis method to get a more objective conclusion based on the research results of many scholars. No research has been found on influencing factors of adoption behavior of mobile readers based on the meta-analysis method. The meta-analysis provides a framework for evaluating the series of studies as a whole, rather than looking at each in isolation [39]. The metaanalysis method has been used in many fields of research, such as medicine, education [40-42], psychology [43], criminology [44], business [45], ecology [46-48], and social science.

The meta-analysis method includes three sections. The first section discusses the systematic review methods needed to support a meta-analysis including the literature search and the screening and coding of eligible studies. The second section discusses best practice meta-analysis including the choice of effect size models, the description of the effect size distribution across studies, and the exploration of variability in effect sizes, also termed heterogeneity, through effect size modeling. The final section discusses the presentation and interpretation of results from a meta-analysis within a systematic review [49].

The process of meta-analysis mainly includes the determination of research topics, the collection and screening of literature, the determination of effect values and the extraction of effect values, the calculation of correlation values, and the analysis and test of results. Among them, the extraction of the effect size and the calculation of the correlation coefficient are the most critical, and the correlation coefficient or path coefficient is mainly used as the effect size for correlation analysis. Due to differences in measurement methods, it is necessary to standardize the effect size in different studies, and use sample size weighting to correct the errors in the correlation coefficients. The correction formula is as shown in equation (1).

$$
r_{+}=\frac{\sum N_{i} r_{i}}{\sum N_{i}}
$$

where $r_{+}$is the sample weighted adjustment correlation coefficient, $r_{i}$ is the $i$-th correlation coefficient, $N_{i}$ is the sample size corresponding to the $i$-th correlation coefficient.

From Fisher $r$ to Fisher $Z$, the following calculation is required. First, the Fisher $Z_{i}$ of each sample is calculated according to the correlation coefficient, as shown in formula (2), and then the sample size of each sample is used for weighting adjustment to obtain Fisher $Z_{+}$, as shown in formula (3). Then, use $Z_{+}$to calculate $r_{z}$, which is the final correlation coefficient, see formula (4). Formulas (5) and (6) are the upper limit and lower limit of the overall estimated value of the correlation coefficient when the confidence level is $95 \%$, and s.d. is the standard deviation under the path.

$$
\begin{aligned}
\text { Fisher's } Z_{i} & =0.5 \times \operatorname{Ln} \frac{1+r_{i}}{1-r_{i}}, \\
\text { Fisher's } Z_{+} & =\frac{\sum N_{i} z_{i}}{\sum N_{i}}, \\
r_{Z} & =\frac{\operatorname{EXP}\left(2 z_{+}\right)-1}{\operatorname{EXP}\left(2 z_{+}\right)+1}, \\
\text { Upper limit }= & r_{z}+1.96 \times \text { s.d., } \\
\text { Lower limit }= & r_{z}-1.96 \times \text { s.d.. }
\end{aligned}
$$

Since the effect value of the comprehensive analysis comes from different documents, in order to test the difference between these results, this paper introduces the FailSafe $N$ (FSN). The larger the value, the more stable the result of the meta-analysis in this paper is, and the less likely the result is to be rejected; if it is less than 0 , it indicates that the research results are unstable and the publication bias is greater. The FSN calculation formula is shown in formula (7), where $N$ represents the number of documents in the meta-analysis sample corresponding to the variable.

$$
N_{f s .05}=\left(\frac{\sum z}{1.645}\right)^{2}-N .
$$

3.2. Choosing Studies. To find a common truth behind conceptually similar studies, researchers apply meta-analysis. The meta-analysis method is a secondary comprehensive analysis and evaluation of an existing single research. Therefore, after determining the related topics of the willingness to adopt or pay for mobile digital reading, it is first necessary to search for related literature in various databases. The following key words Mobile reading, Digital reading, Online reading, Influencing factors, Adopt Intention, Willingness to pay, etc., were searched in Web of science, Google Scholar, PQDT, CNKI, and other domestic and foreign databases. A total of 722 articles were retrieved, including 499 academic journal papers, 141 conference papers, and 82 dissertations. Before further screening of the remaining publications, we established inclusion and exclusion criteria [50]. The selection is based on the following principles:

(1) Remove theoretical research and review papers, and retain empirical research papers. The papers must report the correlation coefficient $(r)$ values or other statistics, such as $F$ - or $t$-statistics, that can be used to calculate correlation coefficients [51]. However, some empirical articles are simple questionnaire surveys and descriptive statistics, or surveys done with grounded theory. Some studies use factor analysis and variance analysis and do not report the correlation coefficient or path coefficient. Because 
these studies cannot extract the effect value of the correlation coefficient, these studies are not included in the research. Qualitative studies, descriptive studies, and studies that were not empirical (literature reviews, letters to the editor, commentaries, calls-to-action, etc.) were not included because they do not provide necessary information for our analyzes [52].

(2) Keep papers using TAM or UTAUT to study mobile reading of adoption behavior or willingness to pay. The dependent variable for the study is about reading willingness and use behavior, and the independent variable is the generation of extended models such as perceived ease of use and perceived usefulness in TAM or UTAUT. Some studies are also about influencing factors, but they are studied from the aspects of equipment conditions (reading conditions, intelligence level), individual characteristics (educational income), advantages of mobile terminal equipment, etc., or some literature studies information quality, information credibility, reputation, cognitive response, and emotional response, which are not included in the scope of our research. Some researchers are about the willingness to continue to use after adoption. Its theoretical basis is the expectation confirmation theory, and the intermediate variable is satisfaction. Such articles are not included in the study of this article.

(3) At present, most of the research on technology acceptance models uses the empirical method of structural equation modeling (SEM) [53], so this research retains papers that use structural equation modeling and provides the correlation coefficient or regression coefficient between the two variables in the research when screening literature. The discriminant validity tables provided in some articles will explain the values in the matrix. If it is not stated whether the values in the matrix are the correlation coefficient or the square of the correlation coefficient, they will be judged based on the data in the discriminant validity table.

In summary, the researchers collected papers relating to influencing factors of adoption behavior of mobile readers to provide a synthesis of scientifically rigorous knowledge in mobile network [40]. When selecting the literature, papers whose topic is about the willingness to adopt behavior or willingness to pay for mobile digital reading, the research model of which is based on TAM or UTAUT and in which the correlation coefficient or regression coefficient between the variables is reported, are included in this research. According to the above principles, a total of 31 Chinese and English papers were selected(Table 1).

3.3. Data Entry and Variable Determination. Systematic reviews follow three basic steps: searching the literature, screening abstracts and full-text documents, and coding included studies. When a meta-analysis is included in a systematic review, researchers need to use methods that will support generalizations to the eligible studies on a topic. Each of the three basic steps must demonstrate that the researcher has attempted to identify, screen, and code all eligible studies on a given topic [49].

Based on the existing variables in 31 papers, this article defines these variables. Perceived usefulness (PU) refers to the usefulness of mobile reading, such as fast reading, increased efficiency, and large amount of information. Perceived ease of use (PEOU) refers to how difficult it is to perceive new technologies, such as using smartphones or Kindles and other readers. Perceived mobility (PM) is similar to perceived convenience. Mobile reading can be read anytime and anywhere. Perceived value (PV) refers to the value of mobile reading. The interface design (SD) refers to a friendly and easy-to-find interface for reading. Perceived entertainment (PE) refers to the use of mobile reading to make oneself happy or physically and mentally pleased, and to perceive fun and entertainment. Social influence (SI) refers to the use of mobile devices for mobile reading affected by friends and colleagues. Recognition adjust (RA) refers to the degree of individual control over the environment and perception of their own behavior, that is, users have self-recognition and judgment on their ability to use mobile numbers. Attitude (ATT) refers to the user's attitude toward using mobile digital reading. Behavior intention (BI) refers to the user's willingness to use mobile digital reading. Actual behavior $(\mathrm{AB})$ refers to the behavior of users actually using mobile digital reading.

When entering the corresponding data, some variables in the literature were merged. Although some variables have different names, those variables whose definitions or connotations are similar are merged into one variable. In addition to the definition of the variable, it is necessary to determine the measurement item. Some definitions may be translated from foreign terminology, which is difficult to understand, and then we should determine the measurement items. For example, the variable "convenience value" in the literature [30] is meant to distinguish between the perceived value and perceived convenience. Using the Chaoxing mobile APP, we can easily search for books and query the borrowing information, that is, mobile reading can be more convenient anytime. According to this principle, the effort expectations in the 31 papers are classified as perceived ease of use (PEOU); performance expectations are classified as perceived usefulness (PU); social norms, subjective norms, social values, community influence, social needs, and network externalities are combined into social influence (SI); convenience, convenience value, and use context are combined into perceived mobility (PM); emotional support, perceived pleasure, perceived interest, and entertainment are combined into perceived entertainment (PE); self-cognition, perceived behavior control, cognitive adjustment, self-evaluation, etc., are combined into cognitive adjustment (RA); and willingness to adopt, intention to use, willingness to pay, and willingness to transfer are combined into behavior intention (BI). If there is a difference in the definition of the same variable in the literature, it shall be combined according to the measurement items in the questionnaire. Some variables have the same name but completely 
TABLE 1: Literature review in the field of mobile reading acceptance.

\begin{tabular}{|c|c|c|c|c|}
\hline Author (Year) & Subject & Participants & $\begin{array}{l}\text { Number of } \\
\text { samples }\end{array}$ & Literature source \\
\hline $\begin{array}{l}\text { *Xiong }(2010) \\
{[5]}\end{array}$ & $\begin{array}{l}\text { The adoption behavior of mobile phone } \\
\text { reading service }\end{array}$ & $\begin{array}{c}\text { College students, masters, doctors, and } \\
\text { other groups }\end{array}$ & 451 & Thesis \\
\hline Pan (2011) [31] & $\begin{array}{c}\text { Acceptance behavior of mobile reading } \\
\text { users }\end{array}$ & Most of them are college students & 411 & Thesis \\
\hline $\begin{array}{l}\text { Lai and Chang } \\
\text { (2011) [22] }\end{array}$ & Attitudes toward using e-book readers & $\begin{array}{l}\text { High school students, college students, } \\
\text { and graduate students }\end{array}$ & 288 & $\begin{array}{l}\text { Online information } \\
\text { review }\end{array}$ \\
\hline $\begin{array}{l}\text { Han et al. (2012) } \\
\text { [15] }\end{array}$ & $\begin{array}{l}\text { The adoption behavior of mobile } \\
\text { readers }\end{array}$ & $\begin{array}{l}\text { High school students, college students, } \\
\text { and graduate students }\end{array}$ & 392 & Soft science \\
\hline Chang (2013) & Mobile reading efficiency & Undergraduate and graduate students & 363 & Library hi tech \\
\hline Liu (2013) [6] & $\begin{array}{l}\text { Influencing factors of children's online } \\
\text { reading behavior }\end{array}$ & $\begin{array}{l}\text { 8- to 12-year-old children and their } \\
\text { parents }\end{array}$ & 256 & Thesis \\
\hline Hao (2013) [7] & The adoption of e-books & $\begin{array}{l}\text { College students, colleges, } \\
\text { undergraduates, masters, doctors, etc. }\end{array}$ & 1034 & Thesis \\
\hline $\begin{array}{l}\text { *Shen }(2019) \\
{[32]}\end{array}$ & $\begin{array}{c}\text { Research on mobile reading adoption } \\
\text { model }\end{array}$ & Most of the users are undergraduates & 426 & $\begin{array}{l}\text { Library science } \\
\text { research }\end{array}$ \\
\hline $\begin{array}{l}\text { * Lao and Gao } \\
\text { (2013) }[16]\end{array}$ & $\begin{array}{l}\text { Factors influencing consumers' } \\
\text { adoption of mobile reading }\end{array}$ & Consumers in Shanghai & 594 & Consumer economy \\
\hline $\begin{array}{l}\text { Chiang and } \\
\text { Chen (2014) } \\
\text { [19] }\end{array}$ & r-book reading willingness & All users & 352 & The electronic library \\
\hline *Ge (2014) [23] & $\begin{array}{c}\text { Behavioral intentions of cell phone } \\
\text { reading }\end{array}$ & $\begin{array}{c}\text { Students of Nankai university and } \\
\text { Tianjin university using mobile phone } \\
\text { libraries }\end{array}$ & 328 & $\begin{array}{l}\text { Library work and } \\
\text { research }\end{array}$ \\
\hline $\begin{array}{l}* \text { Zheng }(2014) \\
{[25]}\end{array}$ & Digital reading behavior & Undergraduates of Fudan university & 977 & Thesis \\
\hline $\begin{array}{l}\text { * Huang and } \\
\text { Fan }(2014)[26]\end{array}$ & Digital reading behavior & Freshman & 302 & Publishing science \\
\hline Ye (2014) [28] & Mobile reading adoption behavior & 18- to 30-year-old youth & 413 & Thesis \\
\hline $\begin{array}{l}\text { Dong (2014) } \\
{[24]}\end{array}$ & Mobile reading behavior & Zhejiang college students & 425 & $\begin{array}{c}\text { Journal of Jiaxing } \\
\text { university }\end{array}$ \\
\hline $\begin{array}{l}\text { Zhang (2014) } \\
{[8]}\end{array}$ & $\begin{array}{l}\text { The adoption behavior of mobile } \\
\text { reading users }\end{array}$ & $\begin{array}{c}\text { Cover users of all ages and education } \\
\text { levels }\end{array}$ & 311 & Thesis \\
\hline $\begin{array}{l}\text { Williams et al. } \\
(2014)[17]\end{array}$ & E-book consumption willingness & All users & 234 & $\begin{array}{l}\text { Journal of computer } \\
\text { information systems }\end{array}$ \\
\hline $\begin{array}{l}\text { Park et al. } \\
\text { (2015) [33] }\end{array}$ & Reading intention of e-books & All users & 219 & The electronic library \\
\hline $\begin{array}{l}\text { Hsiao and Chen } \\
\text { (2015) [10] }\end{array}$ & The efficiency of mobile readers & Third grade & 60 & Library hi tech \\
\hline $\begin{array}{l}\text { * Chen et al. } \\
\text { (2015) [9] }\end{array}$ & $\begin{array}{l}\text { Users' adoption intention of mobile } \\
\text { reading charge service }\end{array}$ & $\begin{array}{l}\text { All users who have been in contact } \\
\text { with mobile reading }\end{array}$ & 190 & Digital library forum \\
\hline $\begin{array}{l}\text { * Mao et al. } \\
\text { (2016) [11] }\end{array}$ & $\begin{array}{c}\text { Research on the adoption behavior of } \\
\text { mobile readers }\end{array}$ & College students & 382 & New century library \\
\hline $\begin{array}{l}\text { * Xu et al. } \\
(2017)[12]\end{array}$ & $\begin{array}{c}\text { Research on the factors influencing the } \\
\text { acceptance behavior of library mobile } \\
\text { reading users }\end{array}$ & $\begin{array}{l}\text { Public library users and university } \\
\text { library users }\end{array}$ & 425 & $\begin{array}{l}\text { Library and } \\
\text { information work }\end{array}$ \\
\hline $\begin{array}{l}\text { Wang et al. } \\
(2017) \text { [27] }\end{array}$ & Willingness to use mobile libraries & All users & 201 & Library hi tech \\
\hline $\begin{array}{l}\text { * Zhang et al. } \\
\text { (2018) }[13]\end{array}$ & $\begin{array}{l}\text { The adoption behavior of mobile } \\
\text { reading APP users }\end{array}$ & All users & 310 & $\begin{array}{l}\text { Digital library theory } \\
\text { and practice }\end{array}$ \\
\hline $\begin{array}{l}\text { Zhao and Xie } \\
(2019)[30]\end{array}$ & $\begin{array}{c}\text { Chaoxing mobile reading platform APP } \\
\text { use intention }\end{array}$ & University student & 379 & $\begin{array}{l}\text { Library and } \\
\text { information work }\end{array}$ \\
\hline $\begin{array}{l}\text { Ji et al. }(2020) \\
{[34]}\end{array}$ & $\begin{array}{c}\text { Influencing factors of social reading } \\
\text { behavior }\end{array}$ & College students and teachers & 195 & Library forum \\
\hline $\begin{array}{l}\text { Chen and Zhu } \\
\text { (2020) [35] }\end{array}$ & $\begin{array}{l}\text { The influencing factors of the transfer } \\
\text { behavior from paper-based reading to } \\
\text { mobile reading }\end{array}$ & College students and teachers & 298 & $\begin{array}{l}\text { Library science } \\
\text { research }\end{array}$ \\
\hline $\begin{array}{l}\text { Liu et al. (2020) } \\
\text { [20] }\end{array}$ & Digital reading intentions & Children aged 9-14 & 252 & Library construction \\
\hline
\end{tabular}


TABLE 1: Continued.

\begin{tabular}{|c|c|c|c|c|}
\hline Author (Year) & Subject & Participants & $\begin{array}{l}\text { Number of } \\
\text { samples }\end{array}$ & Literature source \\
\hline $\begin{array}{l}\mathrm{Li} \text { and } \mathrm{He} \\
(2020)[14]\end{array}$ & $\begin{array}{l}\text { The influence of perceived value of } \\
\text { mobile reading }\end{array}$ & All groups, mainly undergraduates & 335 & $\begin{array}{c}\text { Knowledge } \\
\text { management forum }\end{array}$ \\
\hline $\begin{array}{l}\text { Zhang (2020) } \\
\text { [21] }\end{array}$ & $\begin{array}{l}\text { The influencing factors of mobile } \\
\text { reading }\end{array}$ & All users & 383 & Thesis \\
\hline * Zheng (2020) & $\begin{array}{c}\text { The influencing factors of digital } \\
\text { reading }\end{array}$ & College students & 308 & Thesis \\
\hline
\end{tabular}

The documents marked with $*$ do not provide correlation coefficients between variables, so the calculation is based on the path coefficients provided by them.

different connotations. In order to further determine the meaning of this variable, we can determine the meaning of this variable by checking the measurement items of the questionnaire, and classify them as the corresponding variables in this article according to their connotations. Finally, a total of 194 path relationships were sorted out based on 31 papers, and the total number of samples was 74,964 . The same path relationships were merged, and 58 path relationships among 18 variables were finally determined.

\subsection{Heterogeneity Testing and Model Determination.} Among the determined path relationships, the number of studies greater than or equal to 5 is selected for research, and finally 13 path relationships among 11 variables are selected for meta-analysis. At present, the meta-analysis mainly adopts fixed-effects model or random-effects model, and further chooses fixed-effects or random-effects model through heterogeneity test. Heterogeneity test methods mainly include $Q$ test, $I^{2}$ test, and Tau ${ }^{2}$ test [54]. $Q$ test is based on the test of total variation, assuming that the effect size follows the chi-square distribution, if $P<0.05$, then it is obviously heterogeneous; $\mathrm{Tau}^{2}$ represents the variance of the true effect between groups, and the larger the value, the greater the heterogeneity. The ratio of $\mathrm{Tau}^{2}$ to the total variance is $I^{2}$. Therefore, the $I^{2}$ test mainly reflects the proportion of the true variation of the effect size in the total variation. According to Higgins et al. [55], $I^{2}$ values of $25 \%$, $50 \%$, and $75 \%$ can be regarded as the index range of low, medium, and high heterogeneity.

Meta-analysis is used to combine quantitative data from related research to summarize the results for the whole population, from which it estimates the combined effect of the whole population by synthesizing the weighted means of the effect size from each empirical study. There are two ways to estimate the model to process the meta-analysis: a fixedeffect model and a random-effect model [56]. The fact that the $Q$ statistic calculated in this test is significant $(P<0.05)$ suggests that the studies are heterogeneous. Therefore, random-effects model was taken as a basis for calculating the overall effect size in this study. Furthermore, the values obtained according to the random-effects model are given in the results [57]. It can be seen from Table 2 that the results of the $Q$ significance test between these path relationships are all 0.001 , and the $I^{2}$ is about $75 \%$. Therefore, it is judged that these studies have high heterogeneity, so the random-effect model is selected for subsequent analysis.
TABLE 2: Results of heterogeneity test.

\begin{tabular}{lcccccc}
\hline Variable relationship & $n$ & $Q$ & $\mathrm{~d} f$ & $P$ & $I^{2}$ & $\mathrm{Tau}^{2}$ \\
\hline SD-PEOU & 5 & 380.25 & 4 & 0.001 & 98.95 & 0.293 \\
PEOU-PU & 13 & 237.34 & 12 & 0.001 & 94.94 & 0.058 \\
PU-ATT & 7 & 177.13 & 6 & 0.001 & 96.61 & 0.079 \\
PEOU-ATT & 6 & 105.17 & 5 & 0.001 & 95.25 & 0.057 \\
PU-BI & 21 & 1576.81 & 20 & 0.001 & 98.73 & 0.224 \\
PEOU-BI & 16 & 396.36 & 15 & 0.001 & 96.22 & 0.070 \\
RA-BI & 5 & 160.66 & 4 & 0.001 & 97.51 & 0.112 \\
PE-BI & 7 & 70.91 & 6 & 0.001 & 91.54 & 0.022 \\
PM-BI & 7 & 28.37 & 6 & 0.001 & 78.85 & 0.013 \\
PV-BI & 13 & 270.14 & 12 & 0.001 & 95.56 & 0.064 \\
SI-BI & 14 & 334.96 & 13 & 0.001 & 96.12 & 0.063 \\
ATT-BI & 6 & 362.85 & 5 & 0.001 & 98.62 & 0.177 \\
BI-AB & 6 & 71.17 & 5 & 0.001 & 92.97 & 0.030 \\
\hline
\end{tabular}

In Table 2, $n$ represents the sample size for studying the path relationship, $Q$ represents the $Q$ test, $\mathrm{d} f$ represents the degree of freedom, $P$ is the result of the $Q$ significance test, and $I^{2}$ and $\mathrm{Tau}^{2}$ represent the $I^{2}$ test and Tau ${ }^{2}$ test, respectively.

\section{Results and Discussion}

4.1. Descriptive Statistical Analysis. If the correlation coefficient is reported in the researched literature, the effect size is the correlation coefficient. If the correlation coefficient is not reported in the literature and only the coefficient of the regression path is reported, according to the method of Peterson and Brown [58]: When $r \geq 0 ; \times r=\beta \times 0.98+0.05$; when $r<0, r=0.98-0.05$, where $\beta \in[-0.5,0.5]$, the regression coefficient is converted into the correlation coefficient $r$.

Statistics are carried out by Comprehensive MetaAnalysis (CMA) software, and the descriptive statistical analysis of each path relationship is shown in Table 3. It can be seen from Table 3 that among the research literature on the influencing factors of mobile reading, the path relationship between perceived usefulness and behavioral intention is the most studied, and when the number reaches 21 , only 3 paths are not significant with the significance rate reaching $85.7 \%$; secondly, there are 16 studies on the path relationship between usability and behavioral intention, and 4 paths are not significant with a significant rate of $75 \%$; the third is that the number of researches on the path relationship between social influence and behavioral intention is 14 , and 5 paths are not significant with a significant rate of $64.3 \%$. The significant rate of 8 of 13 path relationships reached $100 \%$. The sample size of each path relationship is between 60 and 1034, and the average sample size is above 293 . 


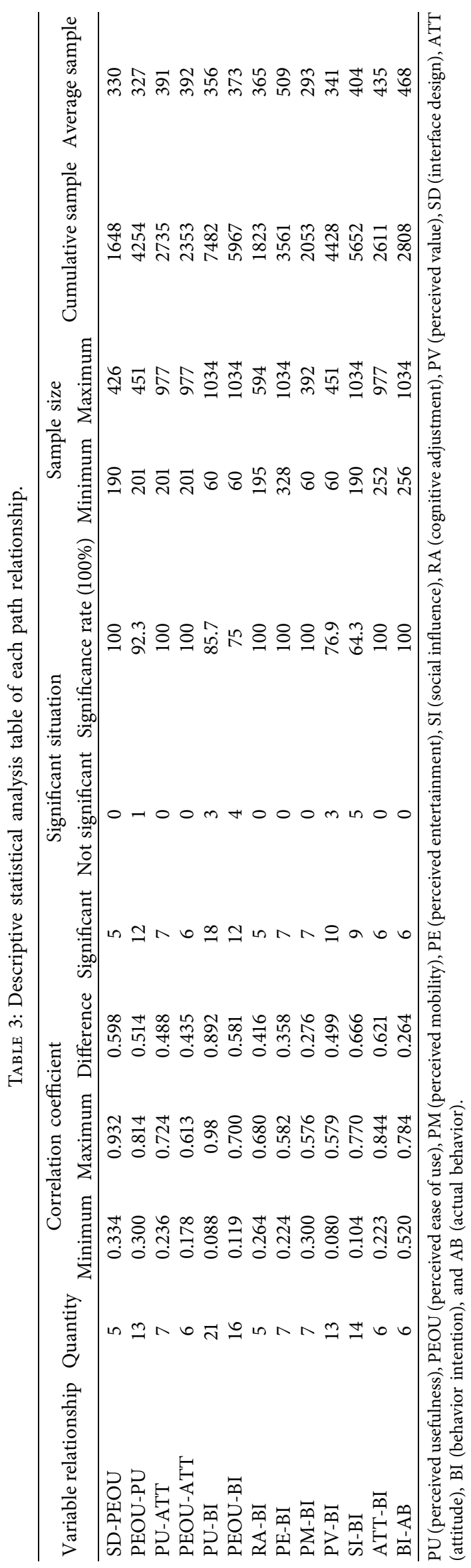


TABLE 4: Cronbach's $\alpha$ analysis.

\begin{tabular}{|c|c|c|c|c|c|}
\hline Variable value & Average reliability & Minimum & Maximum & Variance & Number of studies (a) \\
\hline SD & 0.764 & 0.753 & 0.777 & 0.001 & 3 \\
\hline PEOU & 0.837 & 0.673 & 0.950 & 0.006 & 26 \\
\hline PU & 0.850 & 0.704 & 0.960 & 0.005 & 23 \\
\hline PM & 0.824 & 0.720 & 0.900 & 0.004 & 9 \\
\hline PV & 0.826 & 0.705 & 0.932 & 0.005 & 11 \\
\hline $\mathrm{PE}$ & 0.851 & 0.773 & 0.924 & 0.002 & 12 \\
\hline SI & 0.825 & 0.701 & 0.919 & 0.004 & 18 \\
\hline RA & 0.845 & 0.762 & 0.903 & 0.003 & 6 \\
\hline ATT & 0.813 & 0.737 & 0.954 & 0.006 & 8 \\
\hline BI & 0.863 & 0.725 & 0.998 & 0.004 & 29 \\
\hline $\mathrm{AB}$ & 0.851 & 0.701 & 1.000 & 0.011 & 6 \\
\hline
\end{tabular}

Part of the literature does not report the reliability coefficient, so the number of research variables will be less than the number of variable relationships in the descriptive statistical analysis in Table 3.

TABLE 5: Correlation analysis.

\begin{tabular}{|c|c|c|c|c|c|c|c|}
\hline \multirow{2}{*}{$\begin{array}{l}\text { Path } \\
\text { relationship }\end{array}$} & \multirow{2}{*}{$\begin{array}{l}\text { Correlation } \\
\text { coefficient }\end{array}$} & \multirow{2}{*}{ Fisher's $Z$} & \multicolumn{2}{|c|}{$\begin{array}{l}\text { Correlation 95\% } \\
\text { confidence interval }\end{array}$} & \multirow{2}{*}{$\begin{array}{l}\text { Correlation } \\
Z \text {-value }\end{array}$} & \multirow{2}{*}{$\begin{array}{c}\text { Correlation } \\
P \text {-value }\end{array}$} & \multirow{2}{*}{$\begin{array}{c}\text { Failure safety } \\
\qquad N\end{array}$} \\
\hline & & & $\begin{array}{l}\text { Lower } \\
\text { limit }\end{array}$ & $\begin{array}{l}\text { Upper } \\
\text { limit }\end{array}$ & & & \\
\hline SD-PEOU & 0.714 & 0.896 & 0.396 & 0.879 & 3.681 & 0.001 & 1519 \\
\hline PEOU-PU & 0.557 & 0.629 & 0.457 & 0.643 & 9.143 & 0.001 & 5707 \\
\hline PU-ATT & 0.567 & 0.643 & 0.406 & 0.694 & 5.940 & 0.001 & 1652 \\
\hline PEOU-ATT & 0.449 & 0.484 & 0.280 & 0.591 & 4.835 & 0.001 & 647 \\
\hline PU-BI & 0.591 & 0.679 & 0.442 & 0.708 & 6.523 & 0.001 & 7045 \\
\hline PEOU-BI & 0.431 & 0.461 & 0.316 & 0.533 & 6.769 & 0.001 & 4752 \\
\hline RA-BI & 0.624 & 0.732 & 0.409 & 0.774 & 4.821 & 0.001 & 1125 \\
\hline PE-BI & 0.398 & 0.422 & 0.297 & 0.491 & 7.144 & 0.001 & 1084 \\
\hline PM-BI & 0.456 & 0.492 & 0.375 & 0.530 & 9.850 & 0.001 & 862 \\
\hline PV-BI & 0.374 & 0.394 & 0.247 & 0.489 & 5.439 & 0.001 & 2113 \\
\hline SI-BI & $0.451^{\prime}$ & 0.486 & 0.338 & 0.551 & 7.080 & 0.001 & 4224 \\
\hline ATT-BI & 0.619 & 0.723 & 0.366 & 0.786 & 4.173 & 0.001 & 2232 \\
\hline $\mathrm{BI}-\mathrm{AB}$ & 0.665 & 0.802 & 0.576 & 0.738 & 10.819 & 0.001 & 2490 \\
\hline
\end{tabular}

4.2. Reliability Test Analysis. Before conducting a formal questionnaire survey, the reliability coefficient Cronbach's $\alpha$ of the measurement items and variables of the questionnaire should be reported to prove the reliability of the questionnaire [37]. Most of the 31 papers report the value of Cronbach's $\alpha$. Some papers report the average of all variables or the range from the minimum to the maximum of the Cronbach's $\alpha$, and then the average value is taken as the reliability coefficient of all variables. It can be seen from Table 4 that the reliability coefficients of all variables are distributed between 0.673 and 1 , the minimum average reliability is 0764 , the maximum average reliability is 0.863 , and the maximum variance is 0.011 , indicating that the distribution of reliability coefficients of all variables is relatively stable.

4.3. Effect Size and Failure Safety $N$ Analysis. The effect sizes in this review were inspected to see whether they came from the same population [59]. The correlation coefficient, Fisher's $Z$, and the failure safety $N$ among the influencing factors of mobile reading adoption behavior are shown in Table 5. According to Cohen's [60], when the value of Fisher's $Z$ is between 0.1 and 0.3 , the effect size is Low, when the value is between 0.3 and 0.5 , the effect size is medium, and when the value is greater than or equal to 0.5 , the effect size is high. From the Fisher's $Z$ in Table 5, it can be seen that the minimum Fisher's $Z$ is 0.394 and the maximum Fisher's $Z$ is 0.896 , both of which are above medium, that is, the robustness between these variables is relatively good. In a meta-analysis, there is always a probability for publication bias due to the inclusion of studies with larger effect size; thus, it is mandatory to assess the publication bias before proceeding to the analysis [51]. Accordingly, we employed fail-safe $N$ method [61]. The larger the failure safety $N$, the smaller the deviation of the results of the meta-analysis [62], that is, the size of the failure safety $N$ indicates how many samples are needed to be increased to eliminate the significant correlation between variables [63]. As can be seen from the failure safety $N$ in Table 5,13 sets of variable relationships have passed the failure safety factor test, that is, 1519 studies need to be added to eliminate the significant correlation between the variables SD-PEOU, and the significance of the failure safety factors of other path relationships can be derived from this. The Classic fail-safe $\mathrm{N}$ test showed that 1519 additional studies of adoption behavior of mobile readers would be required to nullify the overall effect size found in the present analysis 


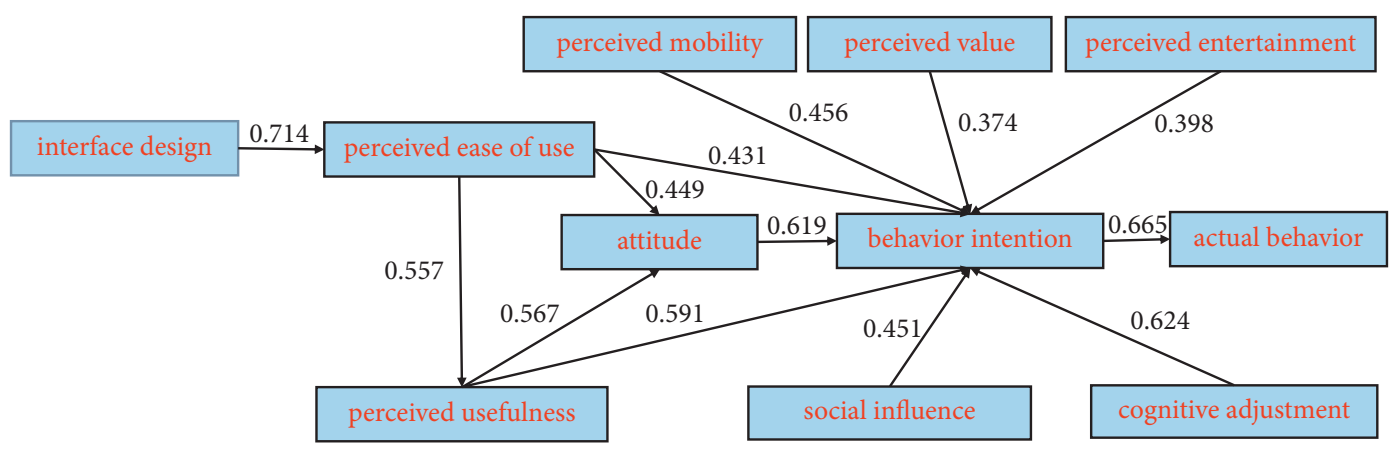

FIgURE 2: Comprehensive model diagram of influencing factors of mobile reading.

[50]. Combined with the analysis results of Tables 3 and 5, the 13 path relationships of 11 variables constitute the comprehensive model diagram of the influencing factors of mobile reading adoption behavior in this article, as shown in Figure 2. Among these 13 path relationships, the path relationships are significant.

As shown in Figure 2, the main influencing factors of the adoption behavior of mobile digital reading users are perceived usefulness, perceived ease of use, perceived mobility, perceived entertainment, social influence, cognitive adjustment, perceived value, use attitude, interface design, etc. Cognitive adjustment has the greatest influence on behavior intention (0.624), followed by attitude (0.619), perceived usefulness $(0.591)$, perceived mobility (0.456), social influence $(0.451)$, perceived ease of use (0.431), perceived entertainment (0.398) and perceived value (0.374); perceived ease of use has a significant positive impact on perceived usefulness (0.557); interface design has a significant positive effect on perceived ease of use (0.714); behavioral intention has a significant positive impact on actual behavior (0.665); perceived usefulness (0.567) and perceived ease of use (0.449) have a significant positive impact on usage attitude.

\section{Conclusion}

This paper conducts a meta-analysis of 31 papers based on Technology Acceptance Model (TAM) and Unified Theory of Acceptance and Use of Technology Model (UTAUT). The 18 variables and 58 path relationships in these papers are studied in a total of 74,964 independent samples. On the basis of descriptive statistical analysis and correlation analysis, 13 path relationships among 11 variables were finally determined, a comprehensive model diagram of factors affecting mobile reading was constructed, and empirical studies were carried out. Compared with the traditional method, the meta-analysis method screens the literature strictly, which can better avoid personal subjective thinking. The method makes the research conclusions more objective and universal. The paper uses the meta-analysis method to get a more objective conclusion based on the research results of many scholars. No research is found on influencing factors of adoption behavior of mobile readers based on the meta-analysis method. Although the meta-analysis method is not a very innovative method, it is probably an innovative research method for this topic. This research has certain significance for scholars, mobile reading service providers, network operators, etc.

(1) The interface design of the reading platform or APP is of great significance to whether users adopt mobile reading. Mobile reading has gradually developed from free reading to paid reading. The interface design of the reading platform or APP has a significant positive impact on the user's perceived ease of use. That is, the user's good experience of using the reading platform will promote the user's willingness to pay for reading on the platform. Platform service providers can consider the user's experience in the design of the platform interface [64]. Only when users experience the friendliness of the interface design can they perceive the ease of use of the platform or APP, so they are willing to adopt mobile reading.

(2) Perceived ease of use is crucial to whether users adopt mobile reading willingness. Only when mobile reading users feel the ease of use of the reading platform or APP, they appreciate its value. The significant positive impact of ease of use has been proved by $92.3 \%$ of the studies, and its failure safety $N$ has reached 5707, indicating that the variable relationship between perceived ease of use and perceived usefulness is very stable and firm. In addition, perceived ease of use has a positive and significant impact on the attitude and willingness of mobile readers, which has also been confirmed in other studies [65].

(3) Perceived mobility has a significant impact on users' willingness to adopt mobile reading. The biggest difference between mobile reading and nonmobile reading is that users can use mobile devices to read anytime and anywhere. The fragmented time in all public places such as high-speed rail, buses, subways, supermarkets, cafes, etc., can be used for mobile reading. All studies believe that perceived mobility has a positive and significant impact on mobile digital readers. Therefore, the promotion of mobile reading is not only related to mobile reading service providers but also related to the quality of network 
operation services. The higher the network quality and the wider the network coverage provided by the three major operators of China Mobile, China Telecom, and China Unicom, the less difficult the popularization of mobile digital reading is.

(4) Perceived pleasure has a positive and significant impact on mobile readers' willingness to adopt. If mobile readers feel happy when using the reading platform or APP, they will be willing to use mobile devices for reading. Of course, the source of this happiness comes from a variety of experiences, such as the smooth use of the platform, the rich reading content that meets the needs of readers, and the interaction with other readers when reading, etc. Therefore, in order for users to experience happiness in reading, it requires the concerted efforts of many parties, such as friendly platform interface, high quality of network services, and selected and diversified reading content.

(5) Social influence has a positive and significant influence on whether users adopt mobile reading. $64.3 \%$ of the studies believe that social influence has a positive and significant impact on mobile reading adoption behavior, and the failure safety $N$ of its path relationship reached 4224 , indicating that 4224 studies need to be added to eliminate the significant correlation between the variables SIBI. That is, this relationship is relatively stable and reliable. Social norms, subjective norms, social values, community influence, social needs, and network externalities are all similar to social influences. Major reading platforms or Apps can establish online reader exchange areas or online comments to allow individual readers to gain recognition and resonate in groups, and the platforms need to actively encourage readers who have already been loyal users of mobile reading platforms to share more to expand the influence on family members, friends, and colleagues around them and expand platform users.

(6) Cognitive adjustment has a significant impact on mobile readers' willingness to adopt. All the studies collected in this article believe that cognitive adjustment has a significant impact on the willingness to use mobile digital reading, and the failure safety $N$ of its path relationship reached 1125 , indicating that 1125 studies need to be added to eliminate the significant correlation between the variables RA-BI. Cognitive adjustment is the individual users' cognition and evaluation of the reading platform. For platform service providers, if they can do a good job of training and operation guidance before the platform is used [66], it will make users feel less difficult and uncomfortable when using the platform, which is effective for users to adopt mobile reading services.

Although meta-analysis provides a comprehensive and generalizable view of previous research in an area, it has some limitations [45]. There are also deficiencies in the research. Due to the lack of data on the mediating and moderating effects of age and gender in the research literature, this article does not study the role of age, gender, experience, voluntary use, and other moderating variables in the integrated technology acceptance model. Therefore, the role of these factors should be considered in future research.

\section{Data Availability}

All the data, models, and code generated or used during the study are included within the submitted article.

\section{Conflicts of Interest}

The authors declare no conflicts of interest.

\section{Acknowledgments}

This article was supported by the National Social Science Foundation's general project "Empirical Research on Teenagers' Digital Reading Behavior in the Era of National Reading" (17BTQ080).

\section{References}

[1] L. Xu, X. Yu, and T. A. Gulliver, "Intelligent outage probability prediction for mobile IoT networks based on an IGWOelman neural network," IEEE Transactions on Vehicular Technology, vol. 70, no. 2, pp. 1365-1375, 2021.

[2] F. D. Davis, "Perceived usefulness, perceived ease of use, and user acceptance of information technology," MIS Quarterly, vol. 13, no. 3, pp. 319-339, 1989.

[3] V. Venkatesh, M. G. Morris, and G. B. Davis, "User acceptance of information technology: toward a unified view," MIS Quarterly, vol. 27, no. 3, pp. 425-478, 2003.

[4] Y. K. Dwivedi, N. P. Rana, K. Tamilmani, and R. Raman, “A meta-analysis based modified unified theory of acceptance and use of technology (meta-UTAUT): a review of emerging literature," Current opinion in psychology, vol. 36, pp. 13-18, 2020.

[5] T. T. Xiong, Research on the Adoption Behavior of Mobile Phone Reading Services among College Students, Huazhong University of Science and Technology, Wuhan, China, 2010.

[6] J. Liu, Research on the Influencing Factors of Children's Online Reading Behavior, Nanjing University, Nanjing, China, 2013.

[7] Y. L. Hao, Research on the Adoption Behavior of E-Books among College Students, Tianjin University, Tianjin, China, 2013.

[8] B. S. Zhang, Research on TAM/TPB User Adoption Behavior for Mobile Reading, Yanshan University, Qinhuangdao, China, 2014.

[9] X. T. Chen, R. Hu, and Q. H. Zhu, "An empirical study on the willingness of users of mobile reading charge service," Digital Library Forum, vol. 11, pp. 11-16, 2015.

[10] K.-L. Hsiao and C.-C. Chen, "How do we inspire children to learn with e-readers?" Library Hi Tech, vol. 33, no. 4, pp. 584-596, 2015.

[11] P. Mao, Q. Kan, and L. Li, "Research on the adoption behavior of mobile reading users," New Century Library, vol. 12, pp. 49-62, 2016.

[12] K. Y. Xu, W. Cui, and X. D. Hong, "Research on the influencing factors of library mobile reading user acceptance behavior," Library and Information Service, vol. 61, no. 15, pp. 43-50, 2017. 
[13] Y. M. Zhang, L. Zheng, and H. O. Liu, "An empirical study on the adoption behavior of mobile reading APP users," Library Theory and Practice, vol. 2, pp. 97-107, 2018.

[14] T. T. Li and J. J. He, "The impact of mobile reading users' perceived value on willingness to pay," Knowledge Management Forum, vol. 5, no. 6, pp. 363-372, 2020.

[15] C. Q. Han, S. Q. Yang, and Y. Z. Cao, “An integrated model of mobile service user adoption behavior: an empirical study based on mobile reading," Soft Science, vol. 26, no. 3, pp. 134-139, 2012.

[16] G. L. Lao and Z. L. Gao, "Analysis of the influencing factors of consumers adopting mobile reading in the era of mobile Internet," Consumer Economics, vol. 29, no. 5, pp. 36-39, 2013.

[17] M. D. Williams, E. L. Slade, and Y. K. Dwivedi, "Consumers' intentions to use e-readers," Journal of Computer Information Systems, vol. 54, no. 2, pp. 66-76, 2014.

[18] C.-C. Chang, "Library mobile applications in university libraries," Library Hi Tech, vol. 31, no. 3, pp. 478-492, 2013.

[19] H.-S. Chiang and C.-C. Chen, "Exploring switch intention of users' reading behaviour," The Electronic Library, vol. 32, no. 4, pp. 434-457, 2014.

[20] J. Liu, L. Y. Chang, W. N. Hua, and C. Huang, "Research on the influencing factors of children's digital reading willingness in remote areas from the perspective of social support," $\mathrm{Li}$ brary Construction, vol. 1-15, 2021.

[21] H. Zhang, Research on the Influencing Factors of Mobile Reading Users' Willingness to Pay, Heilongjiang University, Harbin, China, 2020.

[22] J. Y. Lai and C. Y. Chang, "User attitudes toward dedicated ebook readers for reading," Online Information Review, vol. 35, no. 4, pp. 558-580, 2011.

[23] L. L. Ge, "Research on the intention model of college students' mobile reading behavior," Library Work and Research, vol. 1, no. 6, pp. 17-22, 2014.

[24] W. Y. Dong, "“'Research on the influencing factors and service strategies of college students' mobile reading behavior on mobile phones," Journal of Jiaxing University, vol. 26, no. 5, pp. 136-144, 2014.

[25] Z. L. Zheng, An Empirical Study of College Students' Digital Reading Behavior Model Based on TAM, Fudan University, Shanghai, China, 2014.

[26] Y. K. Huang and W. X. Fan, "Analyze digital reading behavior with the acceptance model of science and technology," Publishing Science, vol. 22, no. 4, pp. 12-19, 2014.

[27] X. Wang, J. Li, M. Yang, Y. Chen, and X. Xu, "An empirical study on the factors influencing mobile library usage in IoT era," Library Hi Tech, vol. 36, no. 4, pp. 605-621, 2018.

[28] F. Y. Ye, Research on the Adoption Behavior of Mobile Reading Users, Nanjing University, Nanjing, China, 2014.

[29] L. Zheng, Research on the Influencing Factors of College Students' Willingness to Pay for Digital Reading Based on the Theory of Social Cognition, Nanjing University, Nanjing, China, 2020.

[30] W. J. Zhao and S. M. Xie, “The relationship between perceived value, satisfaction and behavioral intention of college students in mobile reading: taking Chaoxing mobile reading APP platform as an example," Library and Information Service, vol. 63, no. 3, pp. 98-107, 2019.

[31] W. N. Pan, Analysis of Mobile Phone Reading Status and Research on User Acceptance Behavior, Huazhong University of Science and Technology, Wuhan, China, 2011.
[32] S. Shen, "Research on mobile reading adoption model of university users," Research in Library Science, vol. 3, pp. 8083, 2019.

[33] E. Park, J. Sung, and K. Cho, "Reading experiences influencing the acceptance of e-book devices," The Electronic Library, vol. 33, no. 1, pp. 120-135, 2015.

[34] D. Ji, Z. Guo, and W. Li, "Influencing factors of social reading behavior from the perspective of Flow theory," Library Forum, vol. 40, no. 5, pp. 116-122, 2020.

[35] Y. Chen and Y. Q. Zhu, "Research on the influencing factors of users' transfer behavior from paper reading to mobile reading from the perspective of PPM theory," Library Science Research, vol. 2, pp. 70-80, 2020.

[36] X. Han, "A meta-analysis of integrated technology acceptance models: based on domestic research literature over the past 10 years," Journal of Information, vol. 36, no. 8, pp. 150-174, 2017.

[37] X. H. Ren and Y. Du, "Construction of a meta-analysis model for mobile reading service user behavior influencing factors," Information Science, vol. 37, no. 7, pp. 23-47, 2019.

[38] Y. G. Wang and Y. C. Zhang, "Application comparison of meta-analysis methods in economic management research at home and abroad," Economics and Management, vol. 34, no. 4, pp. 182-190, 2012.

[39] M. Borenstein, L. V. Hedges, and J. P. T. Higgins, Introduction to Meta-Analysis, John Wiley \& Sons Press, Hoboken, NJ, USA, 2021.

[40] M. D. B. Castro and G. M. Tumibay, "A literature review: efficacy of online learning courses for higher education institution using meta-analysis," Education and Information Technologies, vol. 26, no. 2, pp. 1367-1385, 2021.

[41] S. Bissonnette and C. Boyer, "A review of the meta-analysis by Tingir and colleagues (2017) on the effects of mobile devices on learning," Journal of Computer Assisted Learning, no. 5, pp. 1-5, 2021.

[42] M. F. A. Hanid, M. N. H. M. Said, and N. Yahaya, "Learning strategies using augmented reality technology in education: meta-analysis," Universal Journal of Educational Research, vol. 8, no. 5A, pp. 51-56, 2020.

[43] B. Bonnechère, C. Langley, and B. J. Sahakian, "The use of commercial computerised cognitive games in older adults: a meta-analysis," Scientific Reports, vol. 10, no. 1, pp. 15276-15314, 2020.

[44] S.-Y. Cheng, M. Davis, M. Jonson-Reid, and L. Yaeger, "Compared to what? A meta-analysis of batterer intervention studies using nontreated controls or comparisons," Trauma, Violence, \& Abuse, vol. 22, no. 3, pp. 496-511, 2021.

[45] M. Barari, M. Ross, S. Thaichon, and J. Surachartkumtonkun, "A meta-analysis of customer engagement behaviour," International Journal of Consumer Studies, vol. 45, no. 4, pp. 457-477, 2021.

[46] Z. Zhang, Y. Liu, L. Yuan, E. Weber, and M. van Kleunen, "Effect of allelopathy on plant performance: a meta-analysis," Ecology Letters, vol. 24, no. 2, pp. 348-362, 2021.

[47] Z. Pang, G. Zhou, and J. Chong, "Comprehensive metaanalysis of COVID-19 global metabolomics datasets," Metabolites, vol. 11, no. 1, p. 44, 2021.

[48] M. S. C. Sep, M. Vellinga, and R. A. Sarabdjitsingh, "The rodent object-in-context task: a systematic review and metaanalysis of important variables," PLoS One, vol. 16, no. 7, pp. 1-16, 2021.

[49] T. D. Pigott and J. R. Polanin, "Methodological guidance paper: high-quality meta-analysis in a systematic review," Review of Educational Research, vol. 90, no. 1, pp. 24-46, 2020. 
[50] A. D. Ritzhaupt, R. Huang, and M. Sommer, "A meta-analysis on the influence of gamification in formal educational settings on affective and behavioral outcomes," Educational Technology Research and Development, no. 8, pp. 1-30, 2021.

[51] H. I. Maseeh, C. Jebarajakirthy, R. Pentecost, M. Ashaduzzaman, D. Arli, and S. Weaven, "A meta-analytic review of mobile advertising research," Journal of Business Research, vol. 136, pp. 33-51, 2021.

[52] A. R. Piquero, W. G. Jennings, and E. Jemison, "Domestic violence during the COVID-19 pandemic-evidence from a systematic review and meta-analysis," Journal of Criminal Justice, vol. 74, no. C, 2021.

[53] B. Šumak, M. Heričko, and M. Pušnik, "A meta-analysis of e-learning technology acceptance: the role of user types and e-learning technology types," Computers in Human Behavior, vol. 27, no. 6, pp. 2067-2077, 2011.

[54] F. Ding and H. Zhao, "Is the individual subjective well-being of gratitude stronger? A meta-analysis," Advances in Psychological Science, vol. 26, no. 10, pp. 1749-1763, 2018.

[55] J. P. Higgins, S. G. Thompson, J. J. Deeks, and D. G. Altman, "Measuring inconsistency in meta-analyses," BMJ, vol. 327, no. 9, pp. 557-560, 2003.

[56] L. Chen, F. Jia, T. Li, and T. Zhang, "Supply chain leadership and firm performance: a meta-analysis," International Journal of Production Economics, vol. 235, Article ID 108082, 2021.

[57] T. Talan, "The effect of mobile learning on learning performance: a meta-analysis study," Educational Sciences: Theory and Practice, vol. 20, no. 1, pp. 79-103, 2020.

[58] R. A. Peterson and S. P. Brown, "On the use of beta coefficients in meta-analysis," Journal of Applied Psychology, vol. 90, no. 1, pp. 175-181, 2005.

[59] K. Cho, S. Lee, M.-H. Joo, and B. Becker, "The effects of using mobile devices on student achievement in language learning: a meta-analysis," Education Sciences, vol. 8, no. 3, pp. 105-121, 2018.

[60] J. Cohen, Statistical Power Analysis for the Behavioral Sciences, Lawrence Erlbaum Associates, Hillsdale, NJ, USA, 2nd edition, 1988.

[61] C. M. Segijn and M. Eisend, "A meta-analysis into multiscreening and advertising effectiveness: direct effects, moderators, and underlying mechanisms," Journal of Advertising, vol. 48, no. 3, pp. 313-332, 2019.

[62] J. Wu, M. Zeng, F. Z. Liu, and Y. Zhao, "Research on wearable device user adoption behavior based on meta-analysis method," Journal of Information Recording Materials, vol. 7, no. 2, pp. 5-13, 2017.

[63] Y. Kim and R. A. Peterson, "A meta-analysis of online trust relationships in E-commerce," Journal of Interactive Marketing, vol. 38, pp. 44-54, 2017.

[64] M. Wang, Y. X. Li, and W. Cui, "Research on influencing factors of knowledge sharing behavior of mobile reading users," Journal of Library and Information Science, vol. 12, no. 2, pp. $45-51,2019$.

[65] C. H. Deng, L. Zhang, and J. L. Zhang, "Research on mobile business user adoption based on meta-analysis method," Library and Information Service, vol. 56, no. 18, pp. 137-143, 2012.

[66] J. Cheon, S. Lee, S. M. Crooks, and J. Song, "An investigation of mobile learning readiness in higher education based on the theory of planned behavior," Computers \& Education, vol. 59, no. 3, pp. 1054-1064, 2012. 